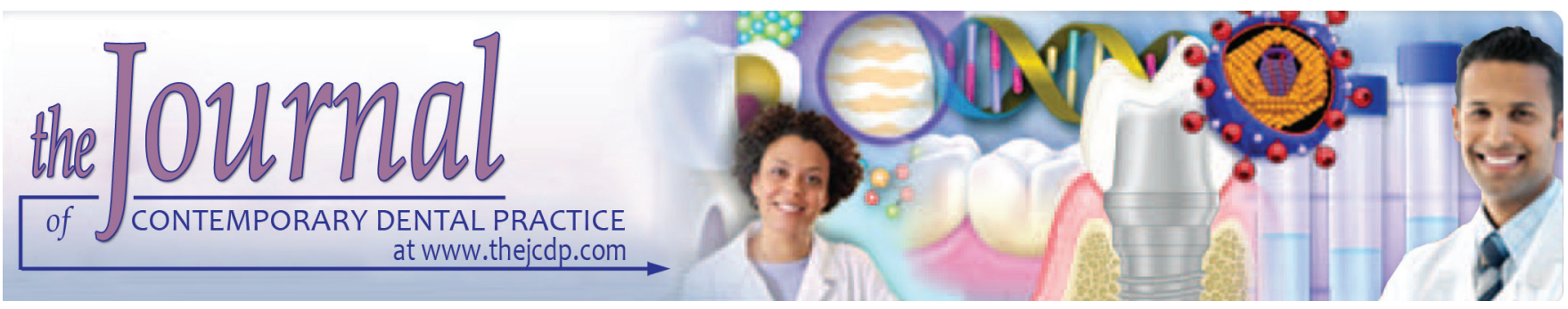

\title{
Caries Assessment Spectrum and Treatment: Would It direct Future Epidemiological Surveys?
}

\author{
${ }^{1}$ Praveen H Bhoopathi, ${ }^{2}$ Sreenivas Voruganti, ${ }^{3}$ Nukala S Suma, ${ }^{4}$ Tejaswini Samudrala \\ ${ }^{5} \mathrm{~B}$ Vinayak Kamath, ${ }^{6}$ Abhishek Jahagirdar
}

\begin{abstract}
Aim: To evaluate caries spectrum among 12- and 15-year-old Indian children using the Caries Assessment Spectrum and Treatment (CAST) index.

Materials and methods: An epidemiological survey of the schoolchildren was carried out in a district in India. A stratified cluster random sampling method was used to select the sample. The caries prevalence of the surveyed population was obtained by using this CAST tool. Chi-square test was used to verify the association between dental fluorosis, socioeconomic status, and age and caries experience. Mann-Whitney U-test was used to compare the caries experience between the two age groups.
\end{abstract}

Results: A total of 2,610 children were examined. The majority of the schoolchildren (12 years: $74.2 \%, 15$ years: $75.5 \%$ ) were healthy concerning their caries experience and the prevalence of the other codes was minimal. The prevalence of dentin carious lesions and the percent of restorable teeth was greater among the 15-year-olds. The mean decayed, missing, and filled teeth (DMFT) of 12- and 15-year-old subjects was calculated to be 0.22 and 0.29 respectively.

Conclusion: The currently surveyed population showed a low caries prevalence and the use of the tool highlighted the caries spectrum in an impressive way.

\footnotetext{
${ }^{1}$ Dental Public Health Unit, Faculty of Dentistry, AIMST University, Bedong, Kedah Darul Aman, Malaysia

${ }^{2,4}$ Department of Public Health Dentistry, Kamineni Institute of Dental Sciences, Hyderabad, Telangana, India

${ }^{3}$ Department of Orthodontics \& Dentofacial Orthopaedics Manipal College of Dental Sciences, Mangaluru, Karnataka India

${ }^{5}$ Goa Dental College and Hospital, Bambolim, Goa, India

${ }^{6}$ Department of Oral Pathology, Dayanand Sagar College of Dental Sciences, Bengaluru, Karnataka, India

Corresponding Author: Praveen H Bhoopathi, Dental Public Health Unit, Faculty of Dentistry, AIMST University, Bedong Kedah Darul Aman, Malaysia, Phone: +60149092688, e-mail: drprav1983.dentist@gmail.com, praveen@aimst.edu.my
}

Clinical significance: A well-designed tool to assess the carious spectrum of an individual or a community, thus enabling the responsible stakeholders to plan an appropriate care that is necessary.

Keywords: Caries Assessment Spectrum and Treatment, Caries epidemiology, Dental caries, Disease progression.

How to cite this article: Bhoopathi PH, Voruganti S, Suma NS, Samudrala T, Kamath BV, Jahagirdar A. Caries Assessment Spectrum and Treatment: Would It direct Future Epidemiological Surveys? J Contemp Dent Pract 2018;19(5):546-553.

Source of support: Nil

Conflict of interest: None

\section{INTRODUCTION}

The recent World Health Organization (WHO) report states that dental caries is a major public health problem in the developing world, which affects a majority of the schoolchildren. ${ }^{1,2}$ On the contrary, there has been a decline in the incidence of dental caries in the developed countries and this change has been attributed to the widespread use of fluorides. ${ }^{3,4}$

In a developing country like India, which has minimal access to oral healthcare facilities, dental caries has become a menace, particularly among the lower socioeconomic sections of the country. ${ }^{5}$ According to the national oral health survey and fluoride mapping, the prevalence of dental caries among 12-and 15-year-old children stood at 53.8 and $63.1 \%$ respectively. ${ }^{6}$ Dental caries is therefore a major public health problem in developing countries and steps have to be taken to shift the focus back to prevention. ${ }^{4,7}$

A valid reason for the perceived lack of interest shown by the policymakers toward addressing this menace can be attributed to the presentation of this issue. The $\mathrm{WHO}^{8}$ criterion for assessing dental caries, which has been widely used in the DMF index ${ }^{9}$ to document the 
dental caries experience of the communities, is grossly uninteresting. This index has quite a few shortcomings, which notably include the nonrepresentation of the restorative/rehabilitative/surgical needs, the stages of the carious lesions, and the complications of untreated dental caries. ${ }^{10,11}$

A few systems have been proposed in the past such as the International Caries Detection and Assessment System (ICDAS) ${ }^{12,13}$ and the PUFA index ${ }^{14}$ to depict the above-highlighted aspects, but unfortunately, they had their share of problems. The ICDAS was cumbersome to use, grossly overestimated the presence of caries, and had difficulties in reporting the two-digit code of this system. ${ }^{11,15,16}$ The PUFA index had its own shortcomings, such as doubts regarding the " $\mathrm{u}$ " component and with the fact that, this index had to be used in combination with other caries assessment criteria. ${ }^{11}$

Considering the above limitations, a new pragmatic and reliable instrument for use in epidemiological surveys was developed and named as the CAST, which covers the complete range of carious lesions: from no carious lesions to the advanced stages of dental caries. ${ }^{11,17}$

The CAST instrument has been validated for face and content by a group of 56 epidemiologists from 24 countries, using the e-Delphi consensus method. ${ }^{18}$. The construct validity and reliability have also been obtained. ${ }^{19,20}$

In today's modern era, there is a changing trend in lifestyles and dietary habits. The adolescents are the ones who are most likely to be affected, primarily in developing countries and therefore it is imperative to assess the entire spectrum of carious lesions using a valid instrument such as the CAST, which will help the policymakers in evaluating the current situation and to implement necessary preventive measures. To the knowledge of the authors, there has not been any documented report on the usage of the CAST tool spanning a large geographical area and therefore, the aim of the present study was to assess the carious spectrum of 12- and 15-year-old school-going children of a district in India.

\section{MATERIALS AND METHODS}

The Institutional Ethics Committee of Kamineni Institute of Dental Sciences (IEC/87B.15) had cleared this crosssectional study and was conducted following the guidelines laid down by the World Medical Association and Helsinki Declaration. The duration of the study was for 5 months.

\section{Study Area and Study Population}

Nalgonda is one of the prominent districts in the newly formed state of Telangana. This area is divided into five administrative/revenue divisions that consist of 59 mandals. This district is a known endemic fluoride belt affected by the high fluoride content in the ground water. $^{21}$

The study subjects comprised of a sample of 12- and 15 -year-old school-going children from the government and private schools within the district.

\section{Sample Size Determination}

According to an earlier published report, the prevalence of dental caries among 12- and 15-year-old children in this region was $56.3 \%{ }^{22}$ Taking $\alpha=5 \%, \beta=20 \%$, and $80 \%$ power, a sample size of 1,085 was calculated. Considering the data loss, a sample of 1,250 was taken for the respective age groups.

A stratified two-stage cluster random sampling method was employed in this cross-sectional study. The district was divided into five administrative divisions. From each division, three mandals were selected from the database of the administration. A list of government and private schools was prepared from the selected mandals. A lottery method of simple random sampling was employed to choose the government and private schools from each division. Emphasis was laid to ensure that all the administrative divisions had an equal share of the sample size.

A set of criteria had been devised to select the study subjects and these are as follows:

\section{Inclusion Criteria}

- Children aged 12 and 15 years at the time of the examination

- Children who are the residents of this district since their birth

\section{Exclusion Criteria}

- Children with systemic diseases

- Children undergoing fixed orthodontic therapy and with severe extrinsic stains, which would make the process of examining tough

A list of 12- and 15-year-old children from these designated schools was obtained and their date of births verified well in advance.

A total of 2,793 students were invited to be a part of the district-wide survey, out of which 2,680 children gave their written consent through their parents, after explaining them regarding the nature of the study. Seventy subjects were excluded as they failed to satisfy the inclusion criteria, bringing down the sample size to 2,610 .

The heads of the selected schools and the District Educational Officer were appraised of the epidemiological 
survey and their permission was obtained before the study commenced.

\section{Examiner Training and Calibration}

Two graduate students (ST and TM) were selected to be a part of the survey. They were initially put through an academic session for 2 hours, wherein they were introduced to the CAST instrument by an oral epidemiologist (BHP) who had participated in a workshop on CAST and had prior experience in carrying out epidemiological surveys (Table 1). The photographs of teeth corresponding to the various codes of the CAST were displayed on a power point. Later, both the examiners were exposed to a set of 15 extracted teeth and were asked to score these teeth according to the criteria. Any discrepancies or doubts, which surfaced, were discussed and sorted out.

In the next stage, the examiners were calibrated for the CAST instrument during which interexaminer agreement was assessed. The examiners were asked to use the assessment tool on 30 schoolchildren, who belonged to the same district, where the epidemiological survey was carried out. The kappa coefficient for the interexaminer

Table 1: Codes and description of the CAST instrument in a hierarchical order ${ }^{17}$

\begin{tabular}{|c|c|c|}
\hline Characteristic & Code & Description \\
\hline & 0 & $\begin{array}{l}\text { Sound. No visible evidence of a distinct } \\
\text { carious lesion }\end{array}$ \\
\hline Sealed & 1 & $\begin{array}{l}\text { Sealed. Pits and fissures have been } \\
\text { at least partially sealed with a sealant } \\
\text { material }\end{array}$ \\
\hline Restored & 2 & $\begin{array}{l}\text { A cavity has been restored with (in) } \\
\text { direct restorative material currently } \\
\text { without a dentin carious lesion and no } \\
\text { fistula/abscess present }\end{array}$ \\
\hline Enamel & 3 & $\begin{array}{l}\text { Distinct visual change in enamel. A } \\
\text { clear carious related discoloration (white } \\
\text { or brown in color) is visible, including } \\
\text { localized enamel breakdown without } \\
\text { clinical signs of dentin involvement }\end{array}$ \\
\hline \multirow[t]{2}{*}{ Dentin } & 4 & $\begin{array}{l}\text { Internal caries related discoloration in } \\
\text { dentin. The lesion appears as shadows } \\
\text { of discolored dentin visible through } \\
\text { enamel, which may or may not exhibit a } \\
\text { visible localized breakdown }\end{array}$ \\
\hline & 5 & $\begin{array}{l}\text { Distinct cavitation into dentine. No } \\
\text { expected pulpal involvement is present }\end{array}$ \\
\hline \multirow[t]{2}{*}{ Pulp } & 6 & $\begin{array}{l}\text { Involvement of pulp chamber. Distinct } \\
\text { cavitation reaching the pulp chamber or } \\
\text { only root fragments is present }\end{array}$ \\
\hline & 7 & $\begin{array}{l}\text { Abscess/fistula. A pus containing swelling } \\
\text { or a pus releasing sinus tract related to } \\
\text { the tooth with pulpal involvement due to } \\
\text { dental caries is present }\end{array}$ \\
\hline Lost & 8 & $\begin{array}{l}\text { The tooth has been removed because } \\
\text { of dental caries }\end{array}$ \\
\hline Others & 9 & $\begin{array}{l}\text { Does not match with any of the other } \\
\text { categories }\end{array}$ \\
\hline
\end{tabular}

agreement was calculated to be 0.81 . These values were considered sufficient to start the epidemiological survey.

The examiners were also trained and calibrated to identify subjects with dental fluorosis, using the Dean's fluorosis index, as this is a known endemic fluoride belt. ${ }^{23}$

The examination of the children was carried out within the school premises using portable dental chairs under natural light. The instruments used were the mouth mirror and the community periodontal index probe as recommended by the WHO for epidemiological surveys. ${ }^{24}$ The condition of each tooth in the oral cavity was evaluated according to the CAST criteria and noted on a survey form, which was specially developed for this study. Trained assistants were provided to both the examiners during the examination procedure. Disinfection protocol was followed during the study to protect the subjects and the examiners from being cross-infected.

Duplicate examinations were carried out during the course of the survey, which involved about $5 \%$ of the subjects being reexamined during those respective days. The kappa coefficient for intraexaminer variability was calculated to be 0.80 and was considered as substantial.

\section{Statistical Tests}

The data were entered into Microsoft Excel worksheet and analyzed using IBM Statistical Package for the Social Sciences version 21. Descriptive statistics in the form of frequencies, percentages, mean, standard deviation, median, and quartiles were presented. Chi-square test was used to test the association between dental fluorosis, socioeconomic status, and age and caries experience. Mann-Whitney U-test was used to compare the caries experience between the two age groups; $\mathrm{p}<0.05$ was considered to be statistically significant.

\section{RESULTS}

A total of 2,680 schoolchildren out of 2,793 agreed to be a part of this epidemiological survey, which works out to be a $95 \%$ response rate among the study subjects. Table 2 depicts the age, gender, and the school-wise distribution of the study subjects.

In Table 3, the prevalence of the CAST codes among 12- and 15-year-old school-going children has been depicted. The data suggest that a majority of the schoolchildren (12 years: $74.2 \%, 15$ years: $75.5 \%$ ) are healthy

Table 2: Age, gender, and school-wise distribution of the study subjects

\begin{tabular}{llll}
\hline & 12-year-old & 15-year-old & Total \\
\hline Males & $658(49.9 \%)$ & $706(54.6 \%)$ & 1,364 \\
Females & $660(50.1 \%)$ & $586(45.4 \%)$ & 1,246 \\
Government & $660(50.1 \%)$ & $656(50.8 \%)$ & 1,316 \\
Private & $658(49.9 \%)$ & $636(49.2 \%)$ & 1,294 \\
\hline
\end{tabular}


Table 3: Prevalence of CAST codes among 12- and 15-yearold study subjects (highest score per mouth used)

\begin{tabular}{llll}
\hline & \multicolumn{2}{c}{ Age } & \\
\cline { 2 - 3 } CAST code & 12 years & 15 years & Total \\
\hline 0 & $978(74.2 \%)$ & $976(75.5 \%)$ & $1,954(74.9 \%)$ \\
1 & 0 & 0 & 0 \\
2 & $11(0.8 \%)$ & $3(0.2 \%)$ & $14(0.5 \%)$ \\
3 & $148(11.2 \%)$ & $81(6.3 \%)$ & $229(8.8 \%)$ \\
4 & $51(3.9 \%)$ & $45(3.5 \%)$ & $96(3.7 \%)$ \\
5 & $62(4.7 \%)$ & $79(6.1 \%)$ & $141(5.4 \%)$ \\
6 & $66(5.0 \%)$ & $107(8.3 \%)$ & $173(6.6 \%)$ \\
7 & 0 & $1(0.1 \%)$ & 1 \\
8 & $2(0.2 \%)$ & 0 & $2(0.1 \%)$ \\
9 & 0 & 0 & 0 \\
\hline Total & 1,318 & 1,292 & 2,610 \\
\hline
\end{tabular}

concerning the caries experience and the prevalence of the other CAST codes is minimal.

The versatility of the CAST tool can be appreciated here (Tables 4 and 5), wherein the prevalence of the dentinal caries lesions (codes 4-7), enamel cum dentinal caries lesions (codes 3-7), the percentage of the teeth which can be restored (codes 4-5), and the percentage of edentulism affecting the study population can be extracted from the data using this novel instrument. The prevalence of dentin carious lesions and the percent of restorable teeth are greater among the 15-year-olds and are statistically significant. The mean number of dentin carious lesions (codes 4-7) was 0.20 for 12-year-olds and 0.28 for 15 -year-olds. The mean enamel carious lesions (codes 3-7) were calculated to be 0.42 for both the age groups. Only 10.1 and $13.2 \%$ of the respective age groups required a restorative therapy (codes 4-5).

Table 5 depicts that $4.6 \%$ of 12 -year-old children had at least one tooth with a carious lesion involving the dentin and $5.8 \%$ of the 15 -year-old children had at least one tooth with a carious lesion involving the dentin.

\section{Prevalence of Dental Fluorosis}

The study subjects belonged to Nalgonda district, which is a known endemic fluoride belt in the state of Andhra Pradesh. Table 6 depicts the distribution of the subjects according to Dean's fluorosis index. The data depicted here indicate a low prevalence of the severe form of dental fluorosis among the schoolchildren (3.9\% for 12-year-olds, $3.3 \%$ for 15 -year-olds).

\section{Relationship between Caries Experience and Dental Fluorosis among the Study Subjects}

The caries experience of the subjects with moderate-tosevere dental fluorosis (Table 7) was lower in comparison to the subjects not affected with dental fluorosis and this association was statistically significant $(p<0.05)$. Similar results were seen, with the caries experience being lower

Table 4: Prevalence of dental caries, percentage of teeth which can be restored, and the proportion of teeth lost among the study subjects

\begin{tabular}{|c|c|c|c|c|c|c|}
\hline & & \multicolumn{2}{|l|}{ Age } & \multirow[b]{2}{*}{ Total } & \multicolumn{2}{|c|}{ Chi-square test } \\
\hline & & 12 years & 15 years & & Chi-square value & $p$-value \\
\hline \multirow[t]{2}{*}{ Codes 4-7 } & Absent & $1,138(86.3 \%)$ & $1,060(82.0 \%)$ & $2,198(84.2 \%)$ & 9.07 & 0.003 \\
\hline & Present & $180(13.7 \%)$ & $232(18.0 \%)$ & $412(15.8 \%)$ & & \\
\hline \multirow[t]{2}{*}{ Codes 3-7 } & Absent & $990(75.1 \%)$ & $979(75.8 \%)$ & $1,969(75.4 \%)$ & 0.15 & 0.69 (NS) \\
\hline & Present & $328(24.9 \%)$ & $313(24.2 \%)$ & $641(24.6 \%)$ & & \\
\hline \multirow[t]{2}{*}{ Codes 4-5 } & Absent & $1,185(89.9 \%)$ & $1,122(86.8 \%)$ & $2,307(88.4 \%)$ & 5.98 & 0.01 \\
\hline & Present & $133(10.1 \%)$ & $170(13.2 \%)$ & $303(11.6 \%)$ & & \\
\hline \multirow[t]{2}{*}{ Code 8} & Absent & $1,316(99.8 \%)$ & $1,292(100.0 \%)$ & $2,608(99.9 \%)$ & - & 0.50 (NS) \\
\hline & Present & $2(0.2 \%)$ & 0 & $2(0.1 \%)$ & & \\
\hline
\end{tabular}

Fisher's exact test

Table 5: Frequency distribution of the study subjects having teeth scored by the CAST codes

\begin{tabular}{llllll}
\hline \multirow{2}{*}{ CAST code } & \multicolumn{2}{c}{12 years } & & \multicolumn{2}{c}{15 years } \\
\cline { 2 - 3 } \cline { 5 - 6 } & $\geq 1$ & $\geq 3$ & & $\geq 1$ & $\geq 3$ \\
1 & 0 & 0 & 0 & 0 \\
2 & $1(0.1 \%)$ & 0 & 0 & 0 \\
3 & $19(1.5 \%)$ & $2(0.2 \%)$ & $7(0.6 \%)$ & $1(0.1 \%)$ \\
4 & $197(14.9 \%)$ & $22(1.7 \%)$ & $133(10.3 \%)$ & $10(0.8 \%)$ \\
5 & $59(4.6 \%)$ & $4(0.4 \%)$ & $75(5.8 \%)$ & $3(0.3 \%)$ \\
6 & $80(6.1 \%)$ & $4(0.3 \%)$ & $108(8.4 \%)$ & $3(0.2 \%)$ \\
7 & $66(5.0 \%)$ & $4(0.2 \%)$ & $107(8.3 \%)$ & $8(0.7 \%)$ \\
8 & 0 & 0 & $1(0.1 \%)$ & 0 \\
9 & $2(0.2 \%)$ & 0 & 0 & 0 \\
\hline
\end{tabular}

Table 6: Distribution of the study subjects according to Dean's fluorosis index

\begin{tabular}{llll}
\hline & \multicolumn{2}{c}{ Age } & \\
\cline { 2 - 3 } Dean's fluorosis index & 12 years & 15 years & Total \\
\hline Mild fluorosis & $309(23.4 \%)$ & $302(23.4 \%)$ & $611(23.4 \%)$ \\
Moderate fluorosis & $284(21.5 \%)$ & $261(20.2 \%)$ & $545(20.9 \%)$ \\
Normal & $161(12.2 \%)$ & $174(13.5 \%)$ & $335(12.8 \%)$ \\
Questionable & $280(21.2 \%)$ & $308(23.8 \%)$ & $588(22.5 \%)$ \\
Severe fluorosis & $52(3.9 \%)$ & $42(3.3 \%)$ & $94(3.6 \%)$ \\
Very mild fluorosis & $232(17.6 \%)$ & $205(15.9 \%)$ & $437(16.7 \%)$ \\
\hline Total & 1,318 & 1,292 & 2,610 \\
\hline
\end{tabular}


Table 7: Caries experience according to the CAST codes and its association with dental fluorosis among the study subjects

\begin{tabular}{|c|c|c|c|c|c|c|}
\hline & \multirow[b]{2}{*}{ Caries } & \multicolumn{4}{|c|}{ Fluorosis } & \multirow[b]{2}{*}{ Total } \\
\hline & & Normal & $\begin{array}{l}\text { Questionable } \\
\text { or very mild }\end{array}$ & Mild & $\begin{array}{l}\text { Moderate or } \\
\text { severe }\end{array}$ & \\
\hline \multirow[t]{3}{*}{12 years } & Absent & $108(67.1 \%)$ & $398(77.7 \%)$ & $232(75.1 \%)$ & $240(71.4 \%)$ & $978(74.2 \%)$ \\
\hline & Present & $53(32.9 \%)$ & $114(22.3 \%)$ & $77(24.9 \%)$ & $96(28.6 \%)$ & $340(25.8 \%)$ \\
\hline & & \multicolumn{4}{|c|}{ Chi-square value $(d f)=9.08(3), p=0.02^{*}$} & \\
\hline \multirow[t]{3}{*}{15 years } & Absent & $112(64.4 \%)$ & $395(77.0 \%)$ & $237(78.5 \%)$ & $232(76.6 \%)$ & $976(75.5 \%)$ \\
\hline & Present & $62(35.6 \%)$ & $118(23.0 \%)$ & $65(21.5 \%)$ & $71(23.4 \%)$ & $316(24.5 \%)$ \\
\hline & & \multicolumn{4}{|c|}{ Chi-square value $(\mathrm{df})=13.93(3), p<0.005^{*}$} & \\
\hline
\end{tabular}

Table 8: School-wise distribution of the caries experience among the study subjects

\begin{tabular}{lllll}
\hline \multicolumn{2}{c}{$\begin{array}{l}\text { Caries } \\
\text { experience }\end{array}$} & \multicolumn{2}{c}{ School } & \\
\cline { 3 - 4 } & Government & Private & Total \\
\hline 12 years & Absent & $460(69.7 \%)$ & $518(78.7 \%)$ & $978(74.2 \%)$ \\
& Present & $200(30.3 \%)$ & $140(21.3 \%)$ & $340(25.8 \%)$ \\
& & Chi-square value (df) $=14.02(1), p<0.001$ \\
15 years & Absent & $476(72.6 \%)$ & $500(78.6 \%)$ & $976(75.5 \%)$ \\
& Present & $180(27.4 \%)$ & $136(21.4 \%)$ & $316(24.5 \%)$ \\
& & \multicolumn{2}{c}{ Chi-square value $(\mathrm{df})=6.40(1), \mathrm{p}<0.05$} \\
\hline
\end{tabular}

in the children enrolled in private schools in comparison with the government-enrolled schoolchildren (Table 8 , $\mathrm{p}<0.05)$.

\section{Representation of the CAST Score via the DMFT}

The results of the CAST instrument can also be converted into the DMFT data. The mean DMFT of 12- and 15 -year-old subjects was calculated to be 0.22 and 0.29 , respectively, as seen in Table 9.

\section{DISCUSSION}

The CAST tool is a novel instrument, designed to quantify the caries experience of an individual or community in a way, which is radically different from the age-old DMFT / DMF surfaces (DMFS) index. This study is the first of its kind wherein the CAST tool has been used in a large-scale epidemiological survey to assess the magnitude of the disease load among 12- and 15-year-old subjects in India.

The entire spectrum of the carious lesions is represented in this study, thereby providing a clear picture of the disease load seen in the survey subjects. It is a refreshing change in comparison to an earlier way of presenting results via the DMFT/DMFS score, which was only a numerical number. Presently, there is no standard method of reporting the results of the CAST tool and, therefore, the authors have stuck to the highest score per mouth as propagated initially by Frencken et $\mathrm{al}^{17}$ and have incorporated other combinations to make the picture clearer.

However, there have been two studies, ${ }^{22,25}$ which have been carried earlier in this geographical area concerning
Table 9: Representation of the CAST data through the DMFT index

\begin{tabular}{llllll}
\hline $\begin{array}{l}\text { Lifetime } \\
\text { caries } \\
\text { experience }\end{array}$ & Age & $n$ & Mean & U statistic & $p$-value \\
\hline $\begin{array}{l}\text { Code }(4-6) \\
+2+8\end{array}$ & 12 years & 1,318 & $0.22(0.61)$ & $822,500.50$ & $0.02^{*}$ \\
+2 years & 1,292 & $0.29(0.73)$ & & \\
\hline \multicolumn{4}{l}{ Mann-Whitney U-test; ${ }^{*} p<0.05$ statistically significant }
\end{tabular}

caries experience by using the DMFT index among 12and 15-year-old population. The flexibility of the CAST instrument is reflected in Table 9 as the data obtained from this tool can also be represented in the standard reporting format, which is the DMFT/DMFS index, thereby enabling the results of this present study to be compared with the earlier ones.

The DMFT for 12- and 15-year-old study subjects in the present study stood at 0.22 and 0.29 , respectively, which indicates that the caries experience for the 15-yearold subjects is higher than 12-year-olds, and this difference was statistically significant $(\mathrm{p}<0.05)$. Shekar et $\mathrm{al}^{22}$ reported a DMFT score of 0.85 for 12 -year-olds and 0.82 for 15-year-olds with an overall caries prevalence of $56.3 \%$. Sukhabogi et $\mathrm{al}^{25}$ presented a mean DMFT score of 0.71 with an overall caries prevalence of $43.4 \%$ for 12 and 15-year-old subjects. Both the studies mentioned have been carried in the same geographical area and the direct inference is that the caries experience of these age groups has reduced over a period and mimics the declining trend in caries experience of the communities worldwide. ${ }^{2}$

The decline in the caries experience has to be carefully analyzed because the subjects had an equal representation from both the government and private schools in the region. The earlier conducted studies in this area had taken a sample only from the government schools and it is a known fact that the economic status does play a role in the lifetime caries experience of an individual. ${ }^{26,27}$ The results of the present study also suggest that the caries experience of the children enrolled in government schools across both the age groups has been higher than their counterparts in the private schools (Table 8, p < 0.001: 12 years, $\mathrm{p}<0.05$ : 15 years). 
However, the decline in the caries prevalence could also be attributed to the gradual increase in and regular home usage of fluoride in toothpaste. ${ }^{28}$

The CAST instrument has been used by research groups such as de Souza et $\mathrm{al}^{29}$ and Baginska et $\mathrm{al}^{30-32}$ across communities in Latin America and the Europe. The focus of these studies was to compare the similarities and differences between the CAST instrument and DMF index and is structurally different from the objectives of the present study. A noteworthy mention is that of the work carried out by Baginska et al ${ }^{32}$ from 6- to 7-year-old Polish children, who assessed the caries prevalence by using the CAST instrument and found a high percentage of the disease load in the surveyed population.

An impressive aspect of this tool is that it also records the presence or absence of sealants and such information reflects a wealth of data on the preventive services available. The currently surveyed population has not been exposed to this preventive care at all, although the current study sample may not be placed under the high caries risk category. Sealants provide the best opportunity for the dental professional to prevent pit and fissure caries within the high caries risk communities and despite the proven benefits, this standard of care is being offered to a minuscule percentage of the population. ${ }^{33}$

In the present study, the prevalence of dental fluorosis was found to be $87 \%$ and is similar when compared with the earlier studies carried out in this region. 22,25,34 The residents of this endemic fluoride belt have been exposed regularly to fluoridated ground water and, therefore, the prevalence of dental fluorosis is expected to be on the higher side. ${ }^{2}$ Of course, assessing the prevalence of dental fluorosis was not the stated objective of the study, but because of the subjects being the residents of a known endemic area, it was considered relevant to quantify the presence of dental fluorosis and its association with the caries experience. No effort has been made to estimate the fluoride levels in the drinking water samples from the administrative divisions of the district and thereby the areas could not be differentiated into low, moderate, or high fluoride areas.

Analyzing the secondary data elicited from this survey is the negative association between dental fluorosis and caries experience (Table 7) between both the age groups, which is in tune with the results obtained from other epidemiological studies. ${ }^{35-39}$ These results are in contrast to the epidemiological data from different communities, which indicated a positive relationship between dental fluorosis and the caries experience. ${ }^{40-42}$ The reasons stated for this positive association were that the teeth with severe dental fluorosis exhibited localized enamel breakdown, which clinically manifests as pitting, predisposing to plaque, and debris accumulation, thereby increasing the risk of demineralization.

Nevertheless, a possible reason for the negative association between caries experience and dental fluorosis could be the fact that only a meager $3.5 \%$ within each age group had been affected with severe dental fluorosis, thus downregulating the association between dental fluorosis and the caries experience. It echoes a similar pattern visualized by Kumar et a ${ }^{43}$ who stated that children with mild to moderate dental fluorosis had a lower caries experience by 41 to $54 \%$.

The authors of this study have found the tool to be extremely convenient to be used in an epidemiological setting as it not a prerequisite for the tooth surface to be dried during the examination. The interexaminer agreement (kappa statistic) was calculated to be 0.81 before the start of the survey, which indicates a good deal in the scoring pattern. ${ }^{44}$ The intraexaminer agreement assessed by the duplicate examinations was found to be 0.84 and 0.86 , respectively, for both the examiners.

To summarize, the study subjects presented with a minimal disease load as elicited by the CAST tool and the authors have found this instrument to be user-friendly in all the parameters and more such epidemiological studies are the need of the hour to ascertain the reliability of this tool with respect to different population subgroups with varying disease load.

\section{ACKNOWLEDGMENTS}

Authors would like to sincerely thank the nonclinical staff of the Department of Public Health Dentistry for their sincere cooperation in completing this research work.

\section{REFERENCES}

1. Peterson PE, Bourgeois D, Ogawa H, Estupinian-Day S, Ndiaye C. The global burden of oral diseases and the risks to oral health. Bull World Health Organ 2005 Sep;83(9):661-669.

2. Peterson PE, Lennon MA. Effective use of the fluorides for the prevention of dental caries in the 21st century: the WHO approach. Community Dent Oral Epidemiol 2004;32(5): 319-321.

3. Marthalar TM. Changes in dental caries 1953-2003. Caries Res 2004 May-Jun;38(3):173-181.

4. World Health Organization. Educational imperatives for oral health personnel: change or decay? Geneva: WHO; 1990.

5. Kulkarni SS, Deshpande SS. Caries prevalence and treatment needs in 11-15 year old children of Belgaum city. J Indian Soc Pedod Prev Dent 2002 Mar;20(1):12-15.

6. National Oral Health Survey and Fluoride Mapping. An epidemiological study of the oral health problems and estimation of fluoride levels in drinking water. New Delhi: Dental Council of India; 2004.

7. Bagramian RA, Garcia-Godoy F, Volpe AR. The global increase in dental caries. A pending public health crisis. Am J Dent 2009 Feb;22(1):3-8. 
8. World Health Organization: Oral Health survey, Basic methods, 4th ed. Geneva: World Health Organization; 1997.

9. Klein H, Palmer CE, Knutson JW. Studies on dental caries 1. Dental status and dental needs of elementary children. Public Health Rep 1938 May;53:751-765.

10. Burt BA. How useful are cross sectional data from surveys of dental caries. Community Dent Oral Epidemiol 1997 Feb;25(1):36-41.

11. Frencken JE, Amorin RG, Faber J, Leal SC. The caries assessment spectrum and treatment (CAST) index: rationale and development. Int Dent J 2011 Jun;61(3):117-123.

12. Pitts N. ICDAS-an international system for caries detection and assessment being developed to facilitate caries epidemiology, research and appropriate clinical management. Community Dent Health 2004 Sep;21(3):193-198.

13. Ismail AI, Sohn W, Tellez M, Amaya A, Sen A, Hasson H, Pitts NB. The International Caries Detection and Assessment System (ICDAS): an integrated system for measuring dental caries. Community Dent Oral Epidemiol 2007 Jun;35(3): 170-178.

14. Monse B, Heinrich-Weltzein R, Benzian H, Holmgren C, van Palenstein Helderman W. PUFA - an index of clinical consequences of untreated dental caries. Community Dent Oral Epidemiol 2010 Feb;38(1):77-82.

15. De Amorim RG, Figueiredo MJ, Leal SC, Mulder J, Frencken JE. Caries experience in a child population in a deprived area of Brazil, using ICDAS II. Clin Oral Invest 2012 Apr;16(2): 513-520.

16. Braga MM, Oliverira LB, Bonini GAVC, Bonecker $\mathrm{M}$, Mendes FM. Feasibility of the International Caries Detection and Assessment system (ICDAS-II) in epidemiological surveys and comparability with the standard World Health Organization criteria. Caries Res 2009; 43(4): 245-249.

17. Frencken JE, de Souza AL, van der Sander WJM, Bronkhorst EM, Leal SC. The Caries Assessment Spectrum and Treatment (CAST) instrument. Community Dent Oral Epidemiol 2013;61:117-123.

18. de Souza AL, van der Sander WJM, Leal S, Frencken JO. The caries assessment spectrum and treatment (CAST) index: face and content validation. Int Dent J 2012 Oct;62(5):270-276.

19. deSouzaAL, LealSC, BronkhorstEM, FrenckenJE, Creugers NH. The caries assessment spectrum and treatment (CAST) instrument: construct validation. Eur J Oral Sci 2014 Apr;122(2): 149-153.

20. de Souza AL, Bronkhorst EM, Creugers NH, Leal SC, Frencken JE. The caries assessment spectrum and treatment (CAST) instrument: its reproducibility in clinical studies. Int Dent J 2014 Aug;64(4):187-194.

21. Brindha K, Rajesh R, Murugan R, Elango L. Fluoride contamination in groundwater in parts of Nalgonda District, Andhra Pradesh, India. Environ Monit Assess 2011 Jan;172(1):481-492.

22. Shekar C, Cheluvaiah MB, Namile D. Prevalence of dental caries and dental fluorosis among the 12 and 15-year-old school children in relation to the fluoride concentration in drinking water in an endemic fluoride belt of Andhra Pradesh. Indian J Public Health 2012 Apr-Jun;56(2):122-128.

23. Dean HT. Classification of mottled enamel diagnosis. J Am Dent Assoc (1922) 1934 Aug;21(8):1421-1426.

24. World Health Organization. Oral health surveys: basic methods. Geneva: World Health Organization; 2013.

25. Sukhabogi JR, Parthasarthi P, Anjum S, Shekar BR, Padma CM, Rani AS. Dental caries and dental caries prevalence among 12 and 15 year old school children in Nalgonda district, Andhra Pradesh, India. Ann Med Health Sci Res 2014 Sep;4(Suppl 3): S245-S252.

26. Fejerskov O, Manji F. Reaction paper: risk assessment in dental caries. In: Bader JD, editor. Risk assessment in dentistry. Chapel Hill (NC): University of North Carolina Dental Ecology; 1990. pp. 215-217.

27. Christensen LB, Twetman S, Sundby A. Oral health in children and adolescents with different socio cultural and socio economic backgrounds. Acta Odontol Scand 2010 Jan;68(1): $34-42$.

28. Brathall D, Hansel-Petersson G, Sundberg H. Reasons for the caries decline: what do the experts believe? Eur J Oral Sci 1996 Aug;104(4):416-422.

29. de Souza AL, Leal SC, Bronkhorst EM, Frencken JE. Assessing caries status according to the CAST instrument and the WHO criterion in epidemiological studies. BMC Oral Health 2014 Sep;14(1):119.

30. Baginska J, Rodakowska E, Kierklo A. Status of the occlusal surfaces of the first permanent molars in 6-8-year-old children evaluated by the CAST and the DMF indices. Eur J Paediatr Dent 2014 Jun;15(2):107-112.

31. Baginska J, Rodakowska E, Milewski R, Kierklo A. Dental caries in primary and permanent molars in 7-8 year old school children evaluated with the caries assessment spectrum and treatment (CAST) index. BMC Oral Health 2014;14(1):1.

32. Baginska J, Rodakowska E, Wilczko M, Kierklo A. Caries assessment spectrum and treatment (CAST) index in the primary molars of 6 to 7 year old Polish children. Oral Health Prev Dent 2016;14(1):85-92.

33. Simensen RJ. Pit and fissure sealant: review of the literature. Pediatr Dent 2002 Sep-Oct;24(5):393-414.

34. Sudhir KM, Prashant GM, Reddy VS, Mohandas U, Chander GN. Prevalence and severity of dental fluorosis among 13 to 15 year old school children of an area known for endemic fluorosis: Nalgonda district of Andhra Pradesh. J Ind Soc Pedod Prev Dent 2009 Oct-Dec;27(4):190-196.

35. Manji F, Fejerskov O. Dental caries in developing countries in relation to the appropriate use of fluoride. J Dent Res 1990 Feb;69(2):733-741.

36. Dean HT. Endemic fluorosis and its relation to dental caries. Pub Health Rep 1938 Aug;53:1443-1452.

37. Horowitz HS, Heifetz SB, Meyers RJ, Driscoll WS, Korts DC. Evaluation of a combination of a self-administered fluoride procedures for control of dental caries in a non-fluoride area: findings after 2 years. Caries Res 1977;11(3):178-185.

38. Yoder KM, Mabelya L, Robison VA, Dunipace AJ, Brizindine EJ, Stookey GK. Severe dental fluorosis in a Tanzanian population consuming water with negligible fluoride concentration. Community Dent Oral Epidemiol 1998 Dec;26:382-393.

39. Driscoll WS, Horowitz HS, Meyers RJ, Heifetz SB, Kingman A, Zimmerman ER. Prevalence of dental caries and dental fluorosis in areas with negligible optimal and above optimal fluoride concentrations in drinking water. J Am Dent Assoc 1986 Jul;113(1):29-33.

40. Grobler SR, Louw AJ, van Kotze TJ. Dental fluorosis and caries experience in relation to three different drinking water fluoride levels in South Africa. Int J Paediatr Dent 2001 Sep;11(5):372-379.

41. Cortes DF, Ellwood RP, O'Mullane DM, Mangalhaes Bastos JR. Drinking water fluoride levels, dental fluorosis 
and caries experience in Brazil. J Pub Health Dent 1996;56(4): 226-228.

42. Wondwossen F, Astrom AN, Bjorvatn K, Bardsen A. The relationship between dental caries and dental fluorosis in areas with moderate and high fluoride drinking water in Ethiopia. Community Dent Oral Epidemiol 2004 Oct;32(5):337-344.
43. Kumar JV, Green EL, Wallace W, Carnahan TA. Trends in dental fluorosis and dental caries prevalences in Newburgh and Kingston, NY. Am J Public Health 1989 May;79(5):565-569.

44. Eklund S, Moller IJ, Leclercq MH. Calibration of the examiners for oral epidemiological surveys. Geneva: World Health Organization; 1993 (ORH/EIS/EPID.93.1). 